\title{
Automated plethysmographic measurement of the ankle-brachial index: a comparison with the doppler ultrasound method
}

\begin{abstract}
Jane H Davies $^{1,2}$ and E Mark Williams ${ }^{1}$
The ankle-brachial index is widely regarded as a pivotal tool for the diagnosis and quantification of peripheral arterial disease. It is, however, plagued by issues relating to its time consuming nature and the skills required to undertake its measurement using the gold standard Doppler ultrasound method. Automated ankle-brachial index measurement devices aim to address such issues; this study aimed to compare the performance of such a device with the Doppler method. Three hundred and eighty participants, with risk factors for cardiovascular disease (mean age: 64, 57\% male), underwent ankle-brachial index measurement firstly with a plethysmographic device followed by the Doppler method. The mean difference between the two methods was $0.016 \pm 0.1,95 \%$ limits of agreement: \pm 0.2 . Sensitivity for detection of peripheral arterial disease, as defined by Doppler ankle-brachial index $\leqslant 0.9$, was $70 \%$, specificity $96 \%$, accuracy $94 \%$. A receiver operating curve revealed an area under the curve of.96, with a 1.04 plethysmographic ankle-brachial index cutoff for optimal sensitivity (98\%) and specificity (75\%). Automated measurements were significantly faster than Doppler measurements $(7 \mathrm{~min} 55 \mathrm{~s}$ vs. $17 \mathrm{~min} 45 \mathrm{~s}$, respectively, $P<0.01$ ). Although is it unclear if the plethysmographic device has sufficient diagnostic accuracy to be used as a stand alone test for the diagnosis of peripheral arterial disease, it is concluded that it can be used as a fast and amenable method of identifying people who require further arterial assessment; the higher cutoff point of 1.04 should be used for this purpose. Hypertension Research (2016) 39, 100-106; doi:10.1038/hr.2015.124; published online 3 December 2015
\end{abstract}

Keywords: doppler ultrasound; peripheral arterial disease; primary care; screening; vascular assessment

\section{INTRODUCTION}

The ankle-brachial index (ABI) has been the foundation of noninvasive assessment of the arterial status of the lower limb for several decades. It is used not only to confirm or refute cases of suspected peripheral arterial disease (PAD), but also as a means of assessment of lower limb wound etiology and to determine if compression therapy is appropriate. Furthermore, the ABI has a burgeoning role as a tool for cardiovascular risk assessment as a substantial evidence base has demonstrated a relationship of abnormal ABI to adverse cardiovascular events ${ }^{1,2}$; current guidelines (American College of Cardiologists/American Heart Association ${ }^{3}$; National Institute for Health and Care Excellence ${ }^{4}$ ) now recommend stringent cardiovascular risk reduction strategies for those with $\mathrm{PAD}$ as defined by an $\mathrm{ABI} \leqslant 0.9$.

However, studies have demonstrated that the ABI is in fact infrequently and often incorrectly used in non-specialist healthcare settings such as primary care. ${ }^{5,6}$ Lack of knowledge and skills to undertake the procedure using a handheld Doppler ultrasound probe and manual sphygmomanometer has been identified as a factor associated with this low use. ${ }^{7}$ In addition, the time consuming nature of Doppler ABI measurement and the need to rest subjects for at least $10 \mathrm{~min}$ before the procedure, also significantly limits its use in busy healthcare settings. ${ }^{5,6}$

In recent years several automated ABI devices have been developed, which require minimal skills to use, and do not require a rest period before measurement, hence reducing the time needed to undertake the procedure. This is achieved by using multiple cuffs to measure arterial systolic pressures of all four limbs simultaneously. The majority of such automated devices use oscillometric technology to define the point when arterial occlusion occurs, the blood pressure at this point is then reported as the systolic pressure; while this method works satisfactorily for measuring brachial pressures, studies have shown that it becomes less accurate when measuring ankle pressures. ${ }^{8,9}$

An alternative method of systolic blood pressure measurement is based on reperfusion plethysmography. A dual-chamber cuff applied to each limb consists of an upper occlusion chamber and a lower detection chamber. When the pressure of the upper occlusion chamber has exceeded arterial systolic pressure, the distal detection chamber detects a gradual decrease in limb volume as a result of blood redistribution in the absence of arterial blood inflow. As the pressure

${ }^{1}$ Faculty of Life Sciences and Education, University of South Wales, Cardiff, UK

${ }^{2}$ Current address: South East Wales Trials Unit (SEWTU), Cardiff University, Cardiff, UK.

Correspondence: Dr JH Davies, South East Wales Trials Unit (SEWTU), Centre for Trials Research, Cardiff University, Cardiff CF14 4YS, UK.

E-mail: daviesj112@cardiff.ac.uk

Received 18 May 2015; revised 16 September 2015; accepted 24 September 2015; published online 3 December 2015 


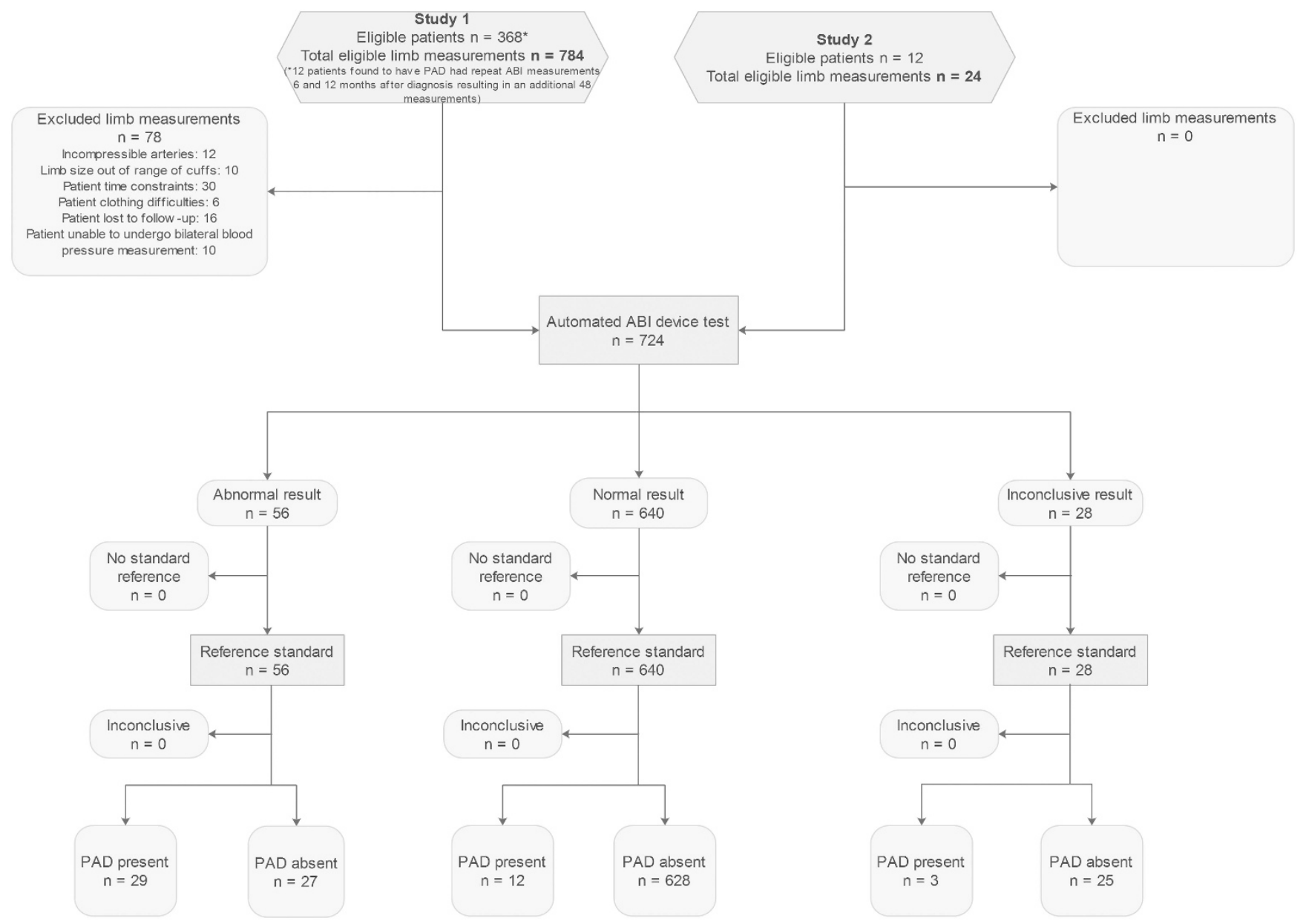

Figure 1 Flow diagram illustrating diagnostic accuracy as per STARD (Standards for Reporting of Diagnostic Accuracy) standard. ${ }^{20}$ A full color version of this figure is available at the Hypertension Research journal online.

in the occlusion chamber is then incrementally reduced and reaches systolic pressure, arterial blood flow to the limb is restored, which is detected as a volume increase in the lower chamber. The pressure in the upper occlusion chamber at the point when this lower chamber volume increase occurs, is taken as the limb arterial systolic pressure.

The aim of this study was to compare the ABI measured with a Doppler ultrasound device $\left(\mathrm{ABI}_{\mathrm{DOP}}\right)$ with the $\mathrm{ABI}$ measured with an automated plethysmographic device (ABI $\mathrm{PLE}$ ). An additional aim was to assess the time taken to measure the $\mathrm{ABI}$ via the two methods.

\section{METHODS}

Data were combined from two studies (Figure 1); one was undertaken in a primary care setting and screened 368 individuals for $\mathrm{PAD}$ as defined by an $\mathrm{ABI}$ of $\leqslant 0.9$. Participants had at least two risk factors for cardiovascular disease but no known cardiovascular disease or diabetes. The second study was undertaken in a secondary care vascular clinic and involved two health professionals measuring the ABIs of 12 individuals who had been referred with suspected PAD. Both studies were approved by the South East Wales Research Ethics Committee (REC No: 12/WA/0075, 12/WA/0242) and written informed consent was gained from each participant.

Each participant underwent bilateral ABI measurement using the plethysmographic device (Dopplex Ability (DA100PB), Huntleigh Healthcare, Cardiff, UK) and Doppler ultrasound (Doppler MD2, $8 \mathrm{MHz}$ probe, Huntleigh Healthcare) with aneroid sphygmomanometery (Welch Allyn Inc, New York, NY, USA). The plethysmographic device was used in accordance with the manufacturers' guidelines and was undertaken first as there was no need for a rest period before testing. The device measured the systolic pressures of all four limbs simultaneously before automatically calculating an ABI for each leg. In the event of a failed measurement, the procedure was repeated if this was acceptable to the participant and if the time schedule of the clinician permitted. The participant was then rested for $5 \mathrm{~min}$ before Doppler ultrasound ABI measurement, which was undertaken in accordance with the American Heart Association's scientific statement for ABI measurement. ${ }^{10}$ All ABI measurements were undertaken by the same clinician (JHD), who is a registered nurse with significant experience in vascular assessment of the lower limb. JHD was blinded to the results of the automated device to ensure this did not influence the subjective Doppler measurements.

The time taken to perform bilateral ABI measurement for each participant was recorded; for the automated plethysmographic device this included the time taken to apply the cuffs to each limb, and for the Doppler method this included a $10 \mathrm{~min}$ rest period before the actual measurement procedure. Equipment used in study measurements was calibrated and maintained in accordance with the manufacturer's guidelines.

\section{Statistical analysis}

Statistical analysis was undertaken using the IBM SPSS software (version 21, New York, NY, USA). Data are presented as mean with s.d. unless otherwise stated. The agreement between the two methods of ABI measurement was assessed by visual inspection of equality plots and Bland-Altman plots with calculation of $95 \%$ confidence interval of agreement. ${ }^{11}$ Sensitivity, specificity, positive predictive values and negative predictive value of the plethysmographic device were calculated, using the Doppler measurements as the reference standard. Data were also assessed to determine if there were any factors which 
Table 1 Population demographics according to each limb ABI measurement

\begin{tabular}{|c|c|c|c|c|}
\hline & All $(\mathrm{n}=724)$ & $\begin{array}{c}A B I_{P L E} \text { result successfully } \\
\text { obtained }(\mathrm{n}=696)\end{array}$ & $\begin{array}{l}\text { No } A B I_{P L E} \text { result } \\
\text { obtained }(n=28)\end{array}$ & P-value \\
\hline \multicolumn{5}{|l|}{ Age (years) } \\
\hline Range & $36-87$ & $36-87$ & $48-81$ & \\
\hline \multicolumn{5}{|l|}{ Gender } \\
\hline PAD status of limb ${ }^{\mathrm{b}} \%(n)$ & & & & $0.345^{\mathrm{e}}$ \\
\hline $\operatorname{PAD}(A B I \leqslant 0.9)$ & $5.7(41)$ & $5.7(40)$ & $3.4(1)$ & \\
\hline Borderline PAD (ABI 0.91-0.99) & $5.8(42)$ & $5.7(40)$ & $7.1(2)$ & \\
\hline Normal (ABI 1.0-1.29) & $79.7(577)$ & $80.2(558)$ & $78.9(22)$ & \\
\hline High $(A B I \geqslant 1.3)$ & $8.8(64)$ & $8.3(58)$ & $10.7(3)$ & \\
\hline
\end{tabular}

Abbreviations: $A B I$, ankle-brachial index; $\mathrm{PAD}$; peripheral arterial disease.

a Defined as systolic $B P \geqslant 140 \mathrm{~mm} \mathrm{Hg}$, and/or diastolic $B P \geqslant 90 \mathrm{~mm} \mathrm{Hg}$, and/or taking anti-hypertensive medications.

baccording to $A B I_{\text {DOP. }}$.

cMann-Whitney U-test.

d $\chi^{2}$ test.

eFisher's exact test.

Statistically significant value is indicated in bold.

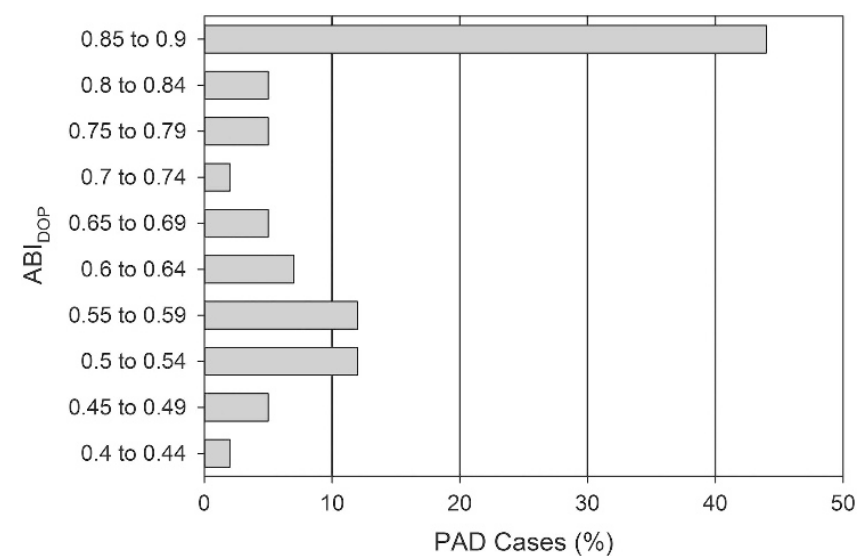

Figure 2 PAD cases: distribution of ABIs. ABI, ankle-brachial index; PAD; peripheral arterial disease.

(i) were associated with the automated device failed measurements and (ii) affected the agreement between the two methods; as continuous data were not normally distributed, this was achieved via the use of the KruskalWallis test.

Categorical data were assessed via use of the $\chi^{2}$ test. A Wilcoxon signed rank test was used to assess the time taken to perform the ABI measurements. Significance was set at $P<0.05$.

\section{RESULTS}

The flow chart of the study is shown in Figure 1. The characteristics of the study population according to each ABI measurement undertaken are shown in Table 1.

\section{Failed measurements}

Although an $\mathrm{ABI}_{\mathrm{DOP}}$ reading was attained for all remaining 724 measurements, there were 28 less $\mathrm{ABI}_{\mathrm{PLE}}$ measures. These failed measurements were associated with the presence of hypertension $(P=0.015$; Table 1$)$. $\mathrm{ABI}_{\mathrm{DOP}}$ ranged from 0.44 to 1.51 $(1.11 \pm 0.14$ mean \pm s.d. $)$, whereas the $\mathrm{ABI}_{\mathrm{PLE}}$ ranged from 0.47 to

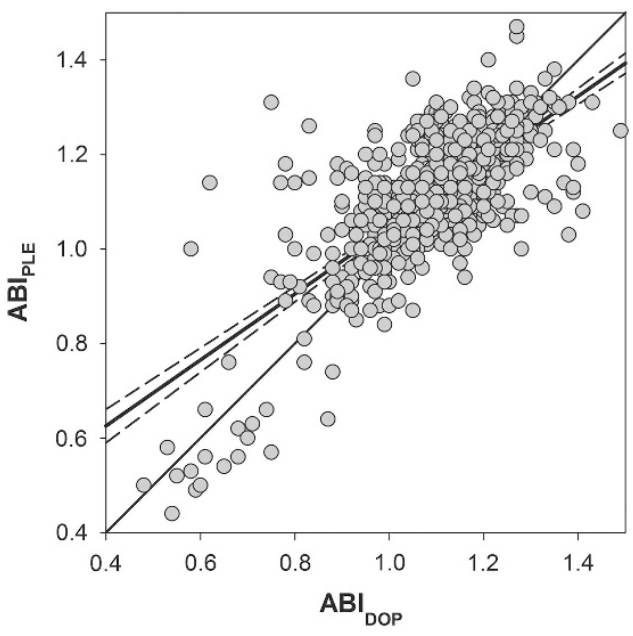

Figure 3 Equality plot showing agreement between $A B I_{D O P}$ and $A B I_{P L E}$. The identity (thin line) and regression (thick line) lines are shown. For the regression line the $95 \% \mathrm{Cl}$ limits are shown as dotted lines, $y=0.35+0.697 x, r=0.74$. ABI, ankle-brachial index; $\mathrm{Cl}$, confidence interval.

$1.49(1.10 \pm 0.14)$. The prevalence of limb measurements indicating $\mathrm{PAD}\left(\mathrm{ABI}_{\mathrm{DOP}} \leqslant 0.9\right)$ was $5.7 \%(n=41$ limbs; Figure 2$)$.

\section{Agreement between the two measurement techniques}

The equality plot of the two measurement methods is shown in Figure 3. The mean difference, or bias was $0.016 \pm 0.1$, and the absolute mean difference was $(0.07 \pm 0.07), 95 \%$ limits of agreement were \pm 0.2 (Figure 4). The $\mathrm{ABI}_{\mathrm{PLE}}$ was higher than the $\mathrm{ABI}_{\mathrm{DOP}}$ in $52 \%$ $(n=361)$ of measurements, lower in $41 \%(n=286)$, and the same for the remaining $7 \%(n=49)$.

There was a gradual increase in bias across the $\mathrm{PAD}$ status groups as the reference standard (Doppler ABI) increased $(P<0.01)$ (Figure 5). In addition, participants with hypertension had a five times greater positive bias than participants who were not hypertensive $(0.032 \mathrm{vs}$. $0.006 ; P=0.018$; Figure 6 ), and similarly, the $95 \%$ limits of agreement 


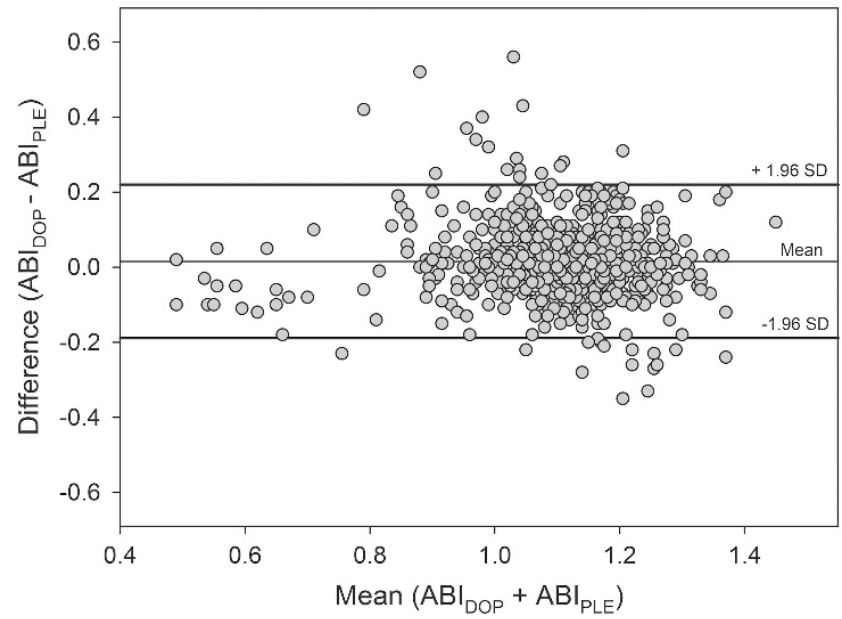

Figure 4 Bland-Altman plot showing agreement between $A B I_{D O P}$ and $A B I_{\text {PLE. }} . A B I$, ankle-brachial index.

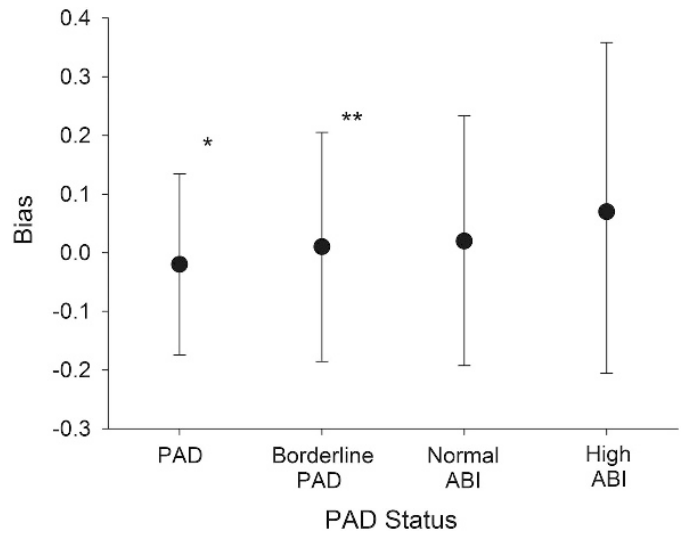

Figure 5 Study bias according to PAD status. A Kruskal-Wallis $H$-test $\left(X^{2}(3)=16.12\right)$ showed significant differences $(P=0.001)$ between groups. A Bonferroni post hoc test revealed that the PAD group* were significantly different from the normal $\mathrm{ABI}$ group $(P=0.04)$ and High $\mathrm{ABI}$ group $(P<0.001)$. The Borderline PAD group** were significantly different from the High $\mathrm{ABI}$ group $(P=0.045)$. $\mathrm{ABI}$, ankle-brachial index; $\mathrm{PAD}$; peripheral arterial disease.

were greater for the hypertensive group than the normotensive group $( \pm 0.23$ vs. $\pm 0.21, P<0.01)$

The sensitivity of the plethysmographic device for diagnosis of PAD, as defined by an $\mathrm{ABI}_{\mathrm{DOP}} \leqslant 0.9$, was $70 \%$, specificity $96 \%$, positive predictive value $52 \%$, negative predictive value $98 \%$ with an overall accuracy $94 \%$. Analysis of a receiver operator characteristic curve (Figure 7) revealed an area under the curve of 0.96 (95\% confidence interval: $0.94-0.98, P<0.001)$. The optimal $\mathrm{ABI}_{\mathrm{PLE}}$ cutoff point for diagnosis of $\mathrm{PAD}$ (as defined by $\mathrm{ABI}_{\mathrm{DOP}} \leqslant 0.9$ ) is 1.04 , which provides a sensitivity of $98 \%$ and specificity of $75 \%$.

The $\mathrm{ABI}_{\mathrm{PLE}}$ measurement procedure was faster $(P<0.01)$ than the $\mathrm{ABI}_{\mathrm{DOP}}$ measurement procedure (which included the rest period), at $7 \mathrm{~min} 55 \mathrm{~s}( \pm 1: 29)$ and $17 \mathrm{~min} 45 \mathrm{~s}( \pm 1: 05)$, respectively.

\section{DISCUSSION}

Data suggest that the plethysmographic device has only moderate sensitivity $(70 \%)$ for detection of PAD. However, this could be partly attributed to the fact that a large proportion of $\mathrm{PAD}$ cases within the sample (44\%) had mild PAD (ABI range: 0.85-0.9; Figure 2) meaning

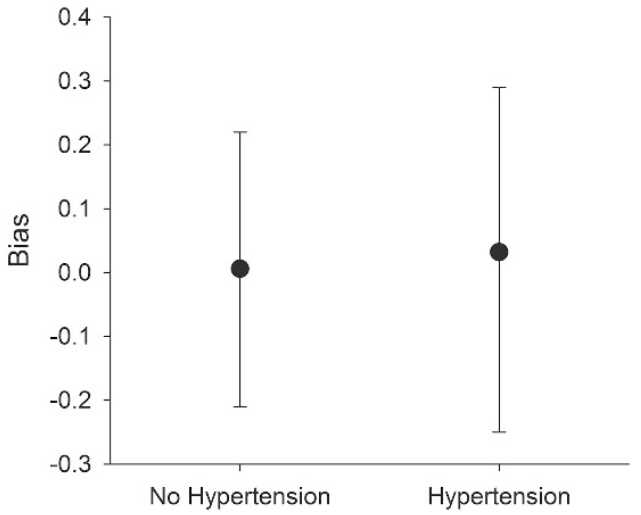

Figure 6 Study bias according to hypertensive status. Mann-Whitney U-test: $U=39742.5, z=-2.363, P=0.018$

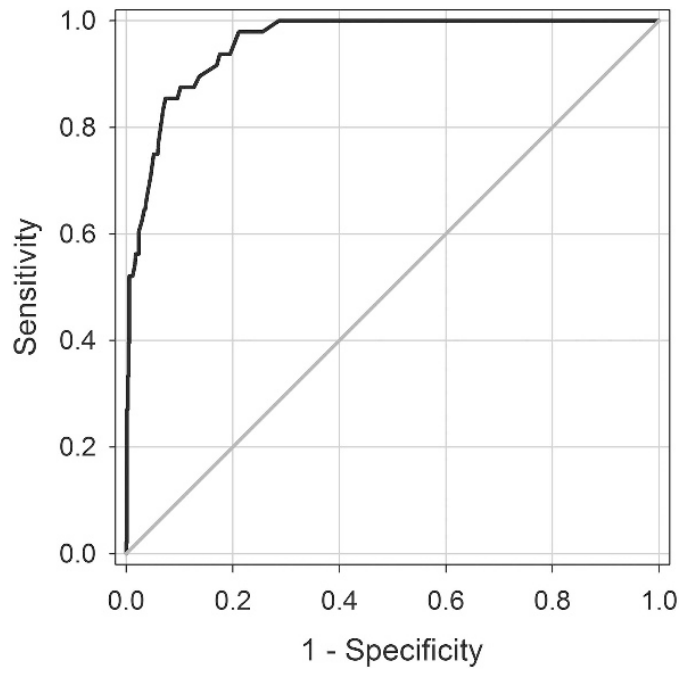

Figure 7 Receiver operating characteristic (ROC) curve for plethysmographic device in diagnosing $P A D$ as defined by $A B I_{D O P} \leqslant 0.9$. Area under curve $=0.96$ (95\% Cl: 0.94-0.98, $P<0.001)$. ABI, ankle-brachial index; $\mathrm{Cl}$, confidence interval; PAD; peripheral arterial disease.

that if the ABI $\mathrm{PLE}$ was only between 0.01 and 0.05 units higher than the $\mathrm{ABI}_{\mathrm{DOP}}$, then a false negative outcome was concluded. It is therefore more useful to consider the receiver operator characteristic curve (Figure 7) to gain more insight into the accuracy of the plethysmographic device. An area under the curve of 0.96 indicates a high degree of accuracy in comparison to the Doppler method as a gold standard. The optimal cutoff point for diagnosis of PAD was $<1.04$, which is considerably higher than the threshold of $\leqslant 0.9$ that is traditionally used for Doppler ABI measurements. However, this appears to be a common finding associated with the use of automated ABI devices; a systematic review and meta-analysis of 25 studies, which assessed the usefulness of oscillometric devices for ABI estimation compared with the conventional Doppler method also concluded that to increase the sensitivity for $\mathrm{PAD}$, a higher threshold $\mathrm{ABI}<1.0$ might be preferable. ${ }^{9}$ The implications of concomitant reduced specificity must, of course, be balanced against this improved sensitivity, as it would result in more patients being misdiagnosed as having PAD or more patients being referred for confirmatory tests such as duplex ultrasound. Both of these outcomes have ethical and financial repercussions. 


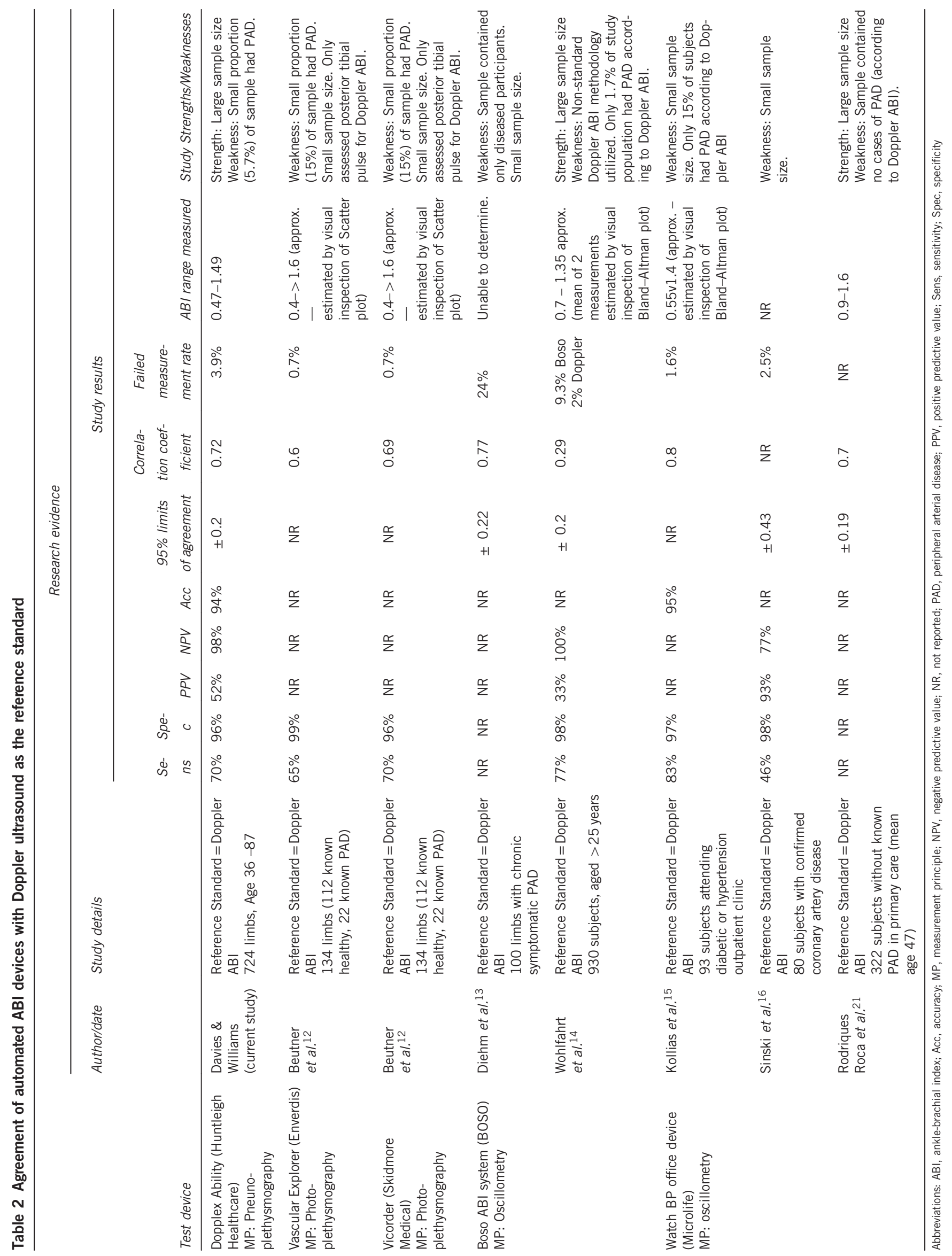


Table 2 summarizes the results of existing studies that examined the agreement of automated ABI devices with Doppler ultrasound. Included devices were restricted to those which are specifically designed for $\mathrm{ABI}$ measurement, which are also portable and designed for use in non-specialist settings; larger devices designed for use within vascular laboratories were not included. Two devices (Vascular Explorer and Vicorder ${ }^{12}$ ) functioned on the principle of photoplethysmography, whereas the remaining all used oscillometry to measure and calculate the ABI. Comparison of data is hindered by study heterogeneity, reporting omissions and differing reporting strategies. It can be seen that $95 \%$ limits of agreement of the Dopplex Ability are either narrower or in the same range as the reported limits of oscillometric devices.

The failed measurement rate $(3.9 \%)$ of the automated device is lower than the reported failed measurement rate pertaining to the BOSO ABI device $\left(24 \%{ }^{13}\right.$ and $\left.9 \%{ }^{14}\right)$, but slightly higher than the failed measurement rate of the Watch BP office device $\left(1.6 \%{ }^{15}\right.$ and $\left.2.5 \%{ }^{16}\right)$. Notably, the ranges of ABIs measured by the Dopplex Ability and the Vascular Explorer and Vicorder devices ${ }^{12}$, which also function on the principle of plethysmography, were greater than the range measured by either of the oscillometric devices (Table 2).

Analysis of the Bland-Altman plot (Figure 4) demonstrated a higher level of agreement between the two measurement techniques at the lower end of the $\mathrm{ABI}$ spectrum and this was shown to be statistically significant (Figures $5, P<0.01$ ). In contrast, oscillometric devices have often been shown to have lower levels of agreement with the Doppler $\mathrm{ABI}$ at the lower end of the ABI spectrum., ${ }^{9}$

The agreement between the two methods was also found to be less in the presence of hypertension $(P=0.018)$. Few studies have examined which factors affect the agreement between automated ABI devices and the Doppler method. A study by Takhashi et al. examined whether gender, age, smoking, alcohol, cardiovascular disease, diabetes, hyperlipidaemia and body mass index were associated with differences between oscillometric and the Doppler method in 113 subjects aged 61-88; they concluded that there were none. ${ }^{17}$ However, Wohlfahrt et al. measured the ABIs of 839 subjects aged $>25$ years using the Doppler method and an oscillometric device and noted that the difference between the methods increased significantly with increasing mean ABI $(r=0.29, P<0.001) .{ }^{14}$

Important potential benefits of automated $\mathrm{ABI}$ systems include their negation of the need for both operator skill and a rest period before the measurement procedure, hence potentially making PAD screening more feasible and amenable. The utility of these devices could, however, be limited by financial considerations, with costs ranging from two to six times more than the typical cost of a handheld Doppler and sphygmomanometer. Several studies have used oscillometric devices that were designed for measuring brachial blood pressures to also measure ankle pressures, which were then used to calculate the ABI. ${ }^{8,18}$ Such devices are not only readily available in the majority of healthcare settings but also cost considerably less than automated ABI systems reviewed in Table 2. However, a systematic review by Verbeck et al. found that such devices showed significantly higher $(P<0.01)$ ABI differences from the Doppler value than the automated devices than were specifically designed for $\mathrm{ABI}$ measurement. ${ }^{8}$ Furthermore, as these standard blood pressure devices do not allow for simultaneous limb blood pressure measurements, the need to rest the patient before the procedure would remain, hence reducing any time savings associated with automated measurements.

\section{Strengths and limitations}

Although the study consisted of a large sample, only a small proportion $(5.7 \%)$ of participants were found to have PAD. Hence, while there has been adequate investigation of how the plethysmographic device performs when measuring the ABIs of healthy subjects, further research is needed to assess its performance in severely diseased populations. The fact that a single clinician undertook all $\mathrm{ABI}$ measurements within the study meant that there were no issues relating to inter-observer variability. However, as the clinician had extensive experience of using the automated device, it is possible that she was able to obtain more accurate results. Furthermore, the subjective nature of Doppler ABI measurements results in susceptibility to observer bias and error, hence perhaps making them an imperfect reference standard in any case. Some authors have addressed this issue by using a superior diagnostic modality such as Duplex ultrasound or computed tomography angiography as the reference standard for such comparative studies. ${ }^{19}$

\section{Perspectives}

There are now more reasons than ever for generic, non-specialist healthcare professionals in settings such as primary care, to measure the ABIs of their patients. Compared with oscillometric ABI devices, the plethysmographic device used here appears to provide improved performance at the lower end of the ABI spectrum. These findings replicate the results of existing studies ${ }^{12}$ of photo-plethysmographic devices, hence suggesting that plethysmography may provide a superior measurement principle for the measurement of low ankle systolic pressures.

Further research is needed to determine if this plethysmographic device can provide sufficient diagnostic accuracy for diagnosis of PAD as a stand alone test. In the meantime, the device can be used as a fast and amenable method of identifying those patients who require further arterial assessment in the form of Doppler ABI measurement, Duplex scan or specialist vascular review. Results have suggested that the higher threshold of $\mathrm{ABI}<1.04$ should be used for this purpose.

\section{CONFLICT OF INTEREST}

JHD's $\mathrm{PhD}$ was part sponsored by Huntleigh Healthcare who supported the reported research via provision of equipment and technical support. Huntleigh Healthcare did not, however, have any role in study design and implementation, nor in the analysis of results and formation of conclusions. EMW declares no conflicts of interest.

\section{ACKNOWLEDGEMENTS}

We would like to thank Cwm Taf University Health Board for their support and Prof Jonathan Richards for hosting the PIPETTE study at Morlais medical practice and Mr Kevin Conway for hosting the IVORY study at the Prince Charles Hospital, Merthyr Tydfil. The research team also acknowledge the support of the National Institute for Health Research through the comprehensive clinical research network. This study was conducted as part of a $\mathrm{PhD}$ project (for JHD) funded by a Knowledge Economy Skills Scholarship (KESS). KESS is a major European Convergence programme, funded by the European Social Fund and led by Bangor University on behalf of the higher education sector in Wales, UK.

1 Tendera M, Aboyans V, Bartelink ML, Baumgartner I, Clement D, Collet JP, Cremonesi A, De Carlo M, Erbel R, Fowkes FG, Heras M, Kownator S, Minar E, Ostergren J, Poldermans D, Riambau V, Roffi M, Rother J, Sievert H, van Sambeek M, Zeller T, Bax J, Auricchio A, Baumgartner H, Ceconi C, Dean V, Deaton C, Fagard R, Funck-Brentano C, Hasdai D, Hoes A, Knuuti J, Kolh P, McDonagh T, Moulin C, Popescu C, Reiner Z, Sechtem U, Sirnes PA, Torbicki A, Vahanian A, Windecker S, 
Agewall S, Blinc A, Bulvas M, Cosentino F, De Backer T, Gottsater A, Gulba D, Guzik TJ, Jonsson B, Kesmarky G, Kitsiou A, Kuczmik W, Larsen ML, Madaric J, Mas JL, McMurray JJ, Micari A, Mosseri M, Muller C, Naylor R, Norrving B, Oto O, Pasierski T, Plouin PF, Ribichini F, Ricco JB, Ruilope L, Schmid JP, Schwehr U, Sol BG, Sprynger M, Tiefenbacher C, Tsioufis C, Van Damme H. ESC Guidelines on the diagnosis and treatment of peripheral artery diseases: Document covering atherosclerotic disease of extracranial carotid and vertebral, mesenteric, renal, upper and lower extremity arteries * The Task Force on the Diagnosis and Treatment of Peripheral Artery Diseases of the European Society of Cardiology (ESC). Eur Heart J 2011; 32: 2851-2906.

2 Yoshitomi R, Nakayama M, Ura Y, Kuma K, Nishimoto H, Fukui A, Ikeda H, Tsuchihashi T, Tsuruya K, Kitazono T. Ankle-brachial blood pressure index predicts cardiovascular events and mortality in Japanese patients with chronic kidney disease not on dialysis. Hypertens Res 2014; 37: 1050-1055.

3 Rooke TW, Hirsch AT, Misra S, Sidawy AN, Beckman JA, Findeiss LK, Golzarian J, Gornik HL, Halperin JL, Jaff MR, Moneta GL, Olin JW, Stanley JC, White CJ, White JV, Zierler RE, Jacobs AK. 2011 ACCF/AHA Focused Update of the Guideline for the Management of Patients With Peripheral Artery Disease (Updating the 2005 Guideline): A Report of the American College of Cardiology Foundation/American Heart Association Task Force on Practice Guidelines. Circulation 2011; 124: 2020-2045.

4 National Institute for Health and Care Excellence. Lower limb peripheral arterial disease: full guideline CG147. National Clinical Guidance Centre: London, 2012.

5 Davies JH, Kenkre J, Williams EM. Current utility of the ankle-brachial index (ABI) in general practice: implications for its use in cardiovascular disease screening. BMC Fam Pract 2014; 15: 69-69.

6 Nicolaï SP, Kruidenier LM, Rouwet EV, Bartelink ML, Prins MH, Teijink JA. Ankle brachial index measurement in primary care: are we doing it right? Br J Gen Pract 2009; 59: 422-427.

7 Mohler ER 3rd, Treat-Jacobson D, Reilly MP, Cunningham KE, Miani M, Criqui MH, Hiatt WR, Hirsch AT. Utility and barriers to performance of the ankle-brachial index in primary care practice. Vasc Med 2004; 9: 253-260.

8 Kornø M, Eldrup N, Sillesen H. Comparison of ankle-brachial index measured by an automated oscillometric apparatus with that by standard Doppler technique in vascular patients. Eur J Vasc Endovasc Surg 2009; 38: 610-615.

9 Verberk WJ, Kollias A, Stergiou GS. Automated oscillometric determination of the ankle-brachial index: a systematic review and meta-analysis. Hypertension Res 2012; 35: 883-891.

10 Aboyans V, Criqui MH, Abraham P, Allison MA, Creager MA, Diehm C, Fowkes FGR, Hiatt WR, Jönsson B, Lacroix P, Marin B, McDermott MM, Norgren L, Pande RL, Preux PM, Stoffers HEJ, Treat-Jacobson D. Measurement and interpretation of the ankle-brachial index: a scientific statement from the American Heart Association. Circulation 2012; 126: 2890-2909.

11 Bland JM, Altman DG. Statistical methods for assessing agreement between two methods of clinical measurement. Lancet 1986; 327: 307-310.

12 Beutner F, Teren A, Gielen S, Schuler G, Wirkner K, Tiller D, Loeffler M, Scholz M. Automated photoplethysmography-based determination of ankle-brachial index: a validation study against Doppler sonography. Clin Res Cardiol 2012; 101: 875-883.

13 Diehm N, Dick F, Czuprin C, Lawall H, Baumgartner I, Diehm C. Oscillometric measurement of ankle-brachial index in patients with suspected peripheral disease: comparison with Doppler method. Swiss Med Wkly 2009; 139: 357-363.

14 Wohlfahrt P, Ingrischova M, Krajcoviechová A, Palous D, Dolejsová M, Seidlerová J, Galovcová M, Bruthans J, Jozífová M, Adámková V, Filipovský J, Cífková R. A novel oscillometric device for peripheral arterial disease screening in everyday practice. The Czech-post MONICA study. Int Angiol 2011; 30: 256-261.

15 Kollias A, Xilomenos A, Protogerou A, Dimakakos E, Stergiou GS. Automated determination of the ankle-brachial index using an oscillometric blood pressure monitor: validation vs. Doppler measurement and cardiovascular risk factor profile. Hypertension Res 2011; 34: 825-830.

16 Sinski M, Styczynski G, Szmigielski C. Automated oscillometric measurement of the ankle-brachial index in patients with coronary artery disease. Hypertension Res 2013; 36: 25-28.

17 Takahashi I, Furukawa K, Ohishi W, Takahashi T, Matsumoto M, Fujiwara S. Comparison between oscillometric- and Doppler-ABI in elderly individuals. Vasc Health Risk Manag 2013; 9: 89-94.

18 Nelson MR, Quinn S, Winzenberg TM, Howes F, Shiel L, Reid CM. Ankle-Brachial Index determination and peripheral arterial disease diagnosis by an oscillometric blood pressure device in primary care: validation and diagnostic accuracy study. BMJ Open 2012; 2: e001689.

19 Ichihashi S, Hashimoto T, Iwakoshi S, Kichikawa K. Validation study of automated oscillometric measurement of the ankle-brachial index for lower arterial occlusive disease by comparison with computed tomography angiography. Hypertension Res2014; 37: 591-594.

20 Bossuyt PM, Reitsma JB, Bruns DE, Gatsonis CA, Glasziou PP, Irwig LM, Lijmer JG, Moher D, Rennie D, de Vet HCW. Towards complete and accurate reporting of studies of diagnostic accuracy: the STARD initiative. Fam Pract 2004; 21 : 4-10.

21 Rodriguez-Roca GC, Villarín-Castro A, Carrasco-Flores J, Artigao-Rodenas LM, Carbayo-Herencia JA, Escobar-Cervantes C, Alonso-Moreno FJ, Segura-Fragoso A, Gómez-Serranillos M, Hernández-Moreno J. Concordance between automated oscillometric measurement of ankle-brachial index and traditional measurement by eco-Doppler in patients without peripheral artery disease. Blood Press 2014; 23: 270-275. 